\title{
Communication ethics in dermatology
}

\section{- Pokhrel DB}

\author{
Address for correspondence \\ Prof. Dinesh Binod Pokhrel \\ Maharajgunj Medical Campus \\ Institute of Medical \\ Tribhuvan University
}

Because of the vast development in communication, media advocacy and growing concern on human/consumer rights and their legal values, every now and then we receive news on medical practitioner's mal behavior with their patient. Many more of such accusations are never notified and hence do not come on the surface. However, some of such surfaced accusations are settled on mutual agreement but others even have to face the court verdict on such issue and then the whole medical fraternities become ashamed off. It clearly shows that there are some practical issues that the medical practitioners are either not aware off or have not given due attention for it. Dermato-venereologist are more often accused for their unethical communication and behavior since they have to handle more sensitive issues concerning the cosmetic appearance of the individual as well as gender sensitive issues in dealing the patients of venereological diseases. Being a medical practitioner, it is important for all of us to fully memorize and abide by the medical oath that we are expected to have taken while entering into this field. Moreover, there are also certain principle ethical codes that the country's medical council has promulgated and made all of us bound to fully comply with.

Besides the laws and regulations governing the ethical communications in our profession, honesty, confidentiality, fairness and quality professionalism are some of the key factors that we all should follow during our communication with the patients as the primary ethical principles. More so, it is important to self-acknowledge the high value of ethical communication with the patients and aim not to be embarrassed due to such communication from either side. To further re-enforce it, let me quote the NCA credo on ethical communication as follows:

"Ethical communication should maintain the correct balance between speaking and listening, the legitimacy of fear and emotional appeal and degree of criticism and praise. A dearth or an overdose of either of the factors could result in unfavorable consequences. The principle of honesty from both sides should completely be applied because any amount of insincerity from either the listener or the speaker would not be prudent". 